\title{
1 A practice theory approach to primary school physical activity: 2 opportunities and challenges for intervention
}

\begin{abstract}
A significant body of critical scholarship exists problematizing the dominant behaviouralindividualist approaches to public health policy and intervention, and practice theories have been noted for their potential in providing an alternative. Children's physical activity in primary school settings continues to be a major area of attention in public health, yet no critical examination of a practice theory approach exists in this context. This paper addresses this gap by applying the prevalent three-elements model of practices to the case of children's school-based physical activity. Drawing on focus group, interview and observation data from pupils, staff and parents at one primary school setting in England, our analysis highlights; first, how the configurations of (a) physical resources (e.g. playground space and equipment), (b) practical know-how (e.g. a skilled understanding of performing the activity), and (c) the socio-cultural significance of practices (e.g. the values and meanings of the activity) impact how, and whether children's physical activity happens, and is sustained or interrupted; and second, by showing how physically active practices are contingent on being simultaneously in harmony or conflict with other routinized practices of the school day. We conclude that the three-elements model offers a helpful framework for understanding school physical activity which de-centres the individual, but that there are challenges in using this analysis to support primary schools as they attempt to enable physically active practices more effectively. Further research is required to develop and evaluate a practice theory approach to promoting children's physical activity.
\end{abstract}

Keywords: physical activity; school; children; social practices; public health. 


\section{Introduction}

27 Epidemiological research and public health policies increasingly position physical activity as being important for population health globally (Das \& Horton, 2016; World Health Organization, 2018) and the lack of parity in physical activity levels between social groups is significantly related to the persistence of health inequalities (Elhakeem,

31 Cooper, Bann, Kuh \& Hardy, 2017). Within this context, ambitions to realise long-term public health goals have led to a focus on children's physical activity. There exists a large body of research delivering interventionist programmes in schools (Love, Adams and van Sluijs, 2019) and numerous government-funded programmes have been implemented internationally (see for example Designed To Move in the United States, Change4Life in the United Kingdom, Get set 4 life in Australia, and Eat Move Live in New Zealand).

Notwithstanding some examples of modest improvements in young people's physical activity as a result of these strategies (Lai, Costigan, Morgan, Lubans, Stodden, Salmon \& Barnett, 2014), a significant body of critical social science scholarship exists problematizing the intervention approaches that are predominantly adopted for physical activity 'behaviour change', often focusing on target groups to encourage their participation in physical activity through the implementation of discrete interventions (Barnfield, 2016; Baum \& Fisher, 2014). These approaches can be characterised by their alignment with the dominant 'ABC' (attitude, behaviour, choice) paradigm in behaviour change policy, which predominantly focuses on targeting the "individuals whose behavioural choices will make the difference" (Shove, 2010, p.1274), supported by targeted communications, social marketing and rewards. collective activities - such as physical activity - might emerge, or fail to emerge, from 50 the social processes of everyday life (Cohn, 2014), including how healthy or unhealthy 
51 activities are synchronised, assembled and combined in particular configurations (Blue,

52 2017). Rather, the responsibility for change is ontologically situated with individuals and their choices (Keane et al., 2017) which logically leads to physical activity interventions such as those which provide children with heart-rate feedback (McManus et al., 2008) and utilise personalised goals and rewards (Miller et al., 2018). Often this means parents or teachers are responsibilised to manage children's health (Burrows and Wright, 2007), but there is also a vision of children who are "agentive as consumers of health-oriented messages and products" (p.88). With specific reference to the potentially harmful impact of intervention on children, there is related critique about the tendency to reframe sociostructural issues as individual problems and 'moral' responsibilities (Burrows and Wright, 2007) which can magnify stigma and shame (LeBesco, 2011; Scambler, 2009) and ultimately contribute to inequalities (Williams, 2017). between mechanisms of aetiology and mechanisms of prevention" (Kelly and Russo, 2018, p.82). Arguably, sustainable 'prevention' of inactivity will only be possible once physical activity is reimagined as emerging from the way social life is organised, rather than as an outcome of the application of a 'dose' of intervention. As such, there is a growing understanding that effective interventions need to account for the complex social processes within which behaviour manifests (Blue, Shove, Carmona \& Kelly, 2016). There is a need to reimagine physical activity as emergent in different ways from different practices, and to intervene in collective conventions towards physical activity rather than simply providing opportunities for participation (Vihalemm et al., 2015). that an interdisciplinary conversation is needed that moves beyond the antagonistic and oppositional tendency of critical social science scholarship and towards a productive 
dialogue between critical social science and public health. In light of this perspective, it is important to recognise that little progress has been made in the development of alternative strategies capable of eschewing the problems associated with the individualistbehavioural paradigm yet meeting the challenge of improving children's physical activity levels for which there is a strong epidemiological mandate (Abarca-Gomez, Abdeen, Hamid et al., 2017).

Intervention approaches that move beyond individualist framings do, of course, already exist and are being more widely accepted (e.g. the 'systems approach' to physical activity highlighted in the WHOs (2018) recent action plan). The socio-ecological model (McLeroy, Bibeau, Steckler \& Glanz, 1988) has been drawn on to shape curriculumbased physical activity interventions such as CHANGE! (Mackintosh, Knowles, Ridgers \& Fairclough, 2011), and the 'whole school approach' embedded in the UK's National Healthy Schools Programme (Department of Health, 2008) was intended to focus on the organisation of school processes for encouraging healthy behaviours. Yet, despite the intentions to deal with wider social processes, schools have found it difficult to manage interventions tackling the established routine ways that physical activity emerges (Adamowitsch, Gugglberger and Dur, 2014) and there is a tendency for 'lifestyle drift' whereby dominant health discourses responsibilising 'behaviours' undermine and shift policy actions away from their original commitments (Powell, Thurston \& Bloyce, 2017).

To support the intentions of public health policy to address broader social processes which shape health, it is crucial for the critical public health community to develop coherent alternatives with utility in research and practice. While school-based intervention strategies are not likely to solve physical inactivity on their own (Love et al., 2019), schools provide a significant socio-material context for children's everyday lives and are already seen as powerful means to institutionalise healthy patterns of behaviour 
101 (Lytle, Seifert, Greenstein and McGovern, 2000). In this context, we seek to explore the

102 value of practice theories as a framework to support physical activity intervention, using

103 the case of children's physical activity in schools as a case study. We seek to contribute

104 to understanding how a practice theory approach can be operationalised to better support

105 schools as they attempt to transition towards enabling physically active practices more

106 effectively.

107

108 Theoretical framing

109 Our approach draws inspiration from repeated calls for a new paradigm of

110 thinking about health behaviour change in which 'health behaviour' is replaced with the

111 term 'health practice' (Nettleton and Green, 2014, p.239), because reifying 'behaviour'

112 "fails to provide any critical insight into what people actually do and why" (Cohn, 2014,

113 p.160). Such calls have led to a flourishing body of work engaging with and extending

114 practice theories, often drawing on foundational concepts such as Bourdieu's (1977;

115 1984) habitus, field and capital and Giddens' (1984) structuration, action and nexus,

116 among others (see Guell et al., 2012; Nettleton and Green, 2014; Blue et al., 2016).

117 Although a number of varieties of practice theories have emerged, Hui, Schatzki and

118 Shove (2016, p.1) note that they generally share familiar assumptions; "that practices

119 consist in organised sets of actions, that practices link to form wider complexes and

120 constellations - a nexus - and that this nexus forms the basic domain of study of the social

121 sciences." One fundamental benefit of drawing on practice theories, as we see it, is that

122 people's physical activity is immediately set in, and constitutive of, a social and material

123 context that involves broad and deeply held meanings that exist largely in circumstances

124 not of any individual person's making. 
Various typologies of practice theory exist (e.g. Reckwitz, 2002; Schatzki, 2001;

126 Warde, 2005) and although there is certainly a lack of consensus among health

127 researchers, we are inclined to agree with Maller (2015) that the version with the most

128 salience for the field in recent years has been Shove et al.'s three-elements model (see

129 Blue et al., 2016; Keane et al., 2017; Meier et al., 2017; Supski et al., 2017). The three-

130 elements model purports that practices 'hang together' (Reckwitz, 2002) when sufficient

131 materials, meanings and competences are both available and coherently intertwined.

132 Materiality refers to the physical resources that often directly implicate the conduct of

133 daily life (Shove \& Pantzar, 2005); meanings refer to the shared ways the world is

134 understood amongst practitioners (Shove et al., 2012) often embedded as an unreflexive

135 sense of the 'right' way to do things (Rettie, Burchell, \& Riley, 2012); and competences

136 are the understandings, knowledge or skills required for a practitioner to successfully

137 perform the practice.

138 Beyond the consideration of elements within each practice, practice theories also

139 attend to the relationships between practices. In line with the three-elements model, they

140 can be in harmony, that is, co-constituting (Shove, Pantzar \& Watson, 2012) and mutually

141 reinforcing (Blue, 2017). In contrast, they can conflict (Schatzki, 2002) in that they can

142 compete for resources such as time and energy. This relational interpretation in terms of

143 how practices emerge, persist, decline and combine (Blue, 2017) offers an opportunity to

144 pose questions as to why some practices succeed in recruiting practitioners while others

145 fail (Keane, Weier, Fraser \& Gartner, 2017), and how some practices become ingrained

146 in the form of deeply held embodied dispositions which are largely beyond reflexive

147 understanding and others do not (Bourdieu, 1985).

A practice theory approach can be seen in a burgeoning stream of health-related

149 research exploring smoking (Blue et al., 2016), vaping (Keane et al., 2017), eating 
150 (Maller, 2015; Twine, 2015), drinking alcohol (Ally, Lovatt, Meier, Brennan \& Holmes, 151 2016; Meier, Warde \& Holmes, 2017; Supski, Lindsay \& Tanner, 2017) and food 152 preparation (Meah \& Jackson, 2018). As a result, some authors offer a manifesto for

153 practice theory-oriented intervention, exalting it as an 'exciting' - if challenging - new

154 territory for public health (Ally et al., 2016; Kelly and Barker, 2016). Commentary has 155 emphasised that interventions should target all three practice elements (and specifically 156 not just 'meanings') (Supski et al., 2017); should attend to how practices intersect (Blue 157 et al., 2016; Blue, 2017; Maller, 2015); should seek to spread and encourage new practices 158 (Maller, 2015); should pay attention to how practices might appeal and recruit new 159 practitioners (Supski et al., 2017); should consider temporal sequencing and spatiality 160 (Twine, 2015); and should consider the characteristics of practice configurations and their amenability to change (Meier et al., 2017).

Despite these advances, few health-related studies offer an empirical basis for thinking through practice theory-oriented intervention (Ally et al., 2016; Blue, 2017;

164 Keane et al., 2017; Supski et al., 2017). Furthermore, there is room for more critical 165 reflection about the possibilities, limitations and practicalities of an approach which 'pays 166 attention' to the nature of practices (Blue et al., 2016, p.43). Furthermore, although there 167 are some examples of social practice theories being applied to physical activity (Blue, 2017; Guell, Panter, Jones and Ogilvie, 2012; Wiltshire, Fullagar \& Stevinson, 2017) this paper is the first attempt at applying the three-elements model of practice theory to

170 children's physical activity in schools.

\section{Research aim and methodology}

172 Our overarching aim was to investigate what practice theories, and specifically the three-

173 elements model, reveal about how children's physical activity emerges over a typical 174 school day. Within this aim, our study had three research questions; (1) which practices 
175 are available to children during a typical school day that require physical activity?

176 how does the configuration of materials, competences and meanings serve to enable or

177 constrain potentially physically active practices, and (3) how are practices enabled or

178 constrained by their inter-relationship to other everyday practices? Through these

179 questions, we sought to understand the dynamics of the practices that demand physical

180 activity in order to set the scene for future intervention activities which would seek not to

181 target children to achieve 'behaviour change' but to target practice configurations

182 themselves.

183 Once institutional ethical approval had been agreed, one state primary school in a

184 rural English town was recruited to participate in the study. In line with comparable

185 studies (e.g. Twine, 2015) the school was viewed as a site through which to examine the

186 interplay of practices; a case study for learning about physical activity from a practice

187 theory perspective. While we acknowledge that conducting our study in a single school

188 imposed limitations on the generalisations that can be made and potential to explore

189 points of difference between contexts, the approach was considered suitable for our

190 research aims and questions, particularly given the range of methods used. The school

191 was recruited based on an existing research relationship and a willingness to engage with

192 innovative projects related to physical activity. Due to the exploratory nature of the

193 research objectives, no other inclusion/exclusion criteria were considered. The school

194 was below average sized (183 pupils) and was deemed 'Good' in the latest Ofsted

195 inspection report (thereby in line with national averages). Almost all pupils identified as

196 White-British and the proportion of pupils for whom the school received the pupil

197 premium (a UK state allowance for pupils from low-income families) was below average.

198 Data collection was undertaken in May 2017 by a team of four researchers through

199 a multi-method qualitative approach. Over two days, researchers recorded observations 
of PE lessons, break and lunchtime activities, afterschool sports clubs and The Daily

201 Mile $^{1}$, to capture a wide range of physically active practices as they occurred in everyday

202 situations. Focus group discussions were carried out with 19 pupils in order to better 203 understand how the children experienced physically active practices. These were 204 conducted during class time in school communal spaces, using engaging and enabling 205 techniques (such as story completion games) to probe the details of children's physical 206 activity. Six additional pupils took part in three separate paired interviews to discuss The 207 Daily Mile. These interviews took place in situ on the playground just after The Daily 208 Mile had finished in order to capture immediate reflections. Three teachers, selected for 209 their availability, participated in interviews and two parents participated in 'walking 210 interviews' whereby one researcher accompanied the parent and child during their walk 211 home from school and asked questions in real-time. Focus groups and interviews lasted 212 between 15 and 30 minutes and were often conducted simultaneously by different 213 members of the research team in order to fit with the compact school schedule. This 214 limited the number of teacher and parent interviews that were possible.

215 We were able to combine and reconcile the diverse methods of data collection by 216 thinking as a 'bricoleur' (Kincheloe, 2005; Wiltshire et al., 2017) and taking methods to 217 be 'tools' to be best used for particular reasons. In this way, observations were helpful in 218 contextualising practices, interviews with adults were particularly helpful in revealing the 219 practice nexus, and focus groups were helpful in learning about the meanings of 220 physically active practices for children.

\footnotetext{
${ }^{1}$ The Daily Mile is a non-government-initiated programme originating in Scotland which involves pupils running, jogging or walking 15 minutes during the school day. Over 3000 schools take part in the UK. Information about the programme is available at thedailymile.co.uk
} 

being imported into NVivo 11 for coding and analysis. Data analysis was carried out by three members of the research team with significant experience in qualitative analysis (FS, GW, SS). After initial exploratory reading of the data, the research team decided to adopt a framework-driven approach to structure the data coding process. This coding was carried out independently by the three researchers before being combined through a consensus meeting and later refined iteratively by email. Initially, researchers identified distinguishable opportunities for physical activity during the school day. These were; walking to/from school, The Daily Mile, classroom lessons, PE lessons, break/lunchtime play, extra-curricular activities and school sport. Each of these opportunities involves a number of practices (e.g. teaching PE/participating in PE). guiding questions based on the three-elements model in order to illuminate how practices are constituted (e.g. What materials enable this practice?). Second, data were then coded using the practice theoretical concepts attending to how practices are inter-related (e.g. Which other competing practices is this practice in conflict with?). A summary of the practice theory framework analysis is provided as supplementary material as Table 1.

\section{Findings}

\section{Materials, competences, meanings and their configuration}

240 The material elements of physically active practices were evident across the seven

241 identified opportunities throughout the school day. For parents and children walking to

242 school, for example, the journey relied upon the materiality of the road and pavement layout being conducive to walking (made more challenging if the parent also had a pram), and the distance between school and home. One parent noted that the journey was "safe" but also that the walk to school was more difficult than the walk from school because it 
246 involved much more uphill walking. During the walking interview, children were 247 observed climbing on low walls alongside the pedestrian path, and running and skipping 248 during parts of the journey without road traffic. Noticing the various points of ease and 249 difficulty during the walk home highlighted the importance of physical geography, 250 accessibility and urban planning to the maintenance of this practice; issues that are not 251 evenly distributed across geographical areas and social groups (Meier et al., 2017). Where 252 the material and spatial context provided opportunity for play for children, often with 253 friends or siblings, this also shaped their emotional relationship with their active 254 commute.

The physical objects in the playground were significant during playtime activities,

256 including climbing apparatus, sports equipment, concrete and grass sections of the 257 playground surface, and painted lines on the concrete surface for games - all of which can be considered as resources that are likely to be differentially provided for across diverse school contexts. Different playground areas became meaningful for the children as they created games during their breaks and as lunchtime supervisors enforced rules

261 about the suitability of those games. Also, material elements of the playground were meaningful in different ways to school leaders. For example, recently purchased matting, laid over a small section of grass, connected two concrete courtyards and created a full

264 circuit for The Daily Mile. This overcame teacher associations with poor safety. 265 Previously, wet grass prevented the activity from happening at all, indicating the privilege 266 of health and safety policies within the physical activity domain. This additional matting 267 served to enable The Daily Mile, suggesting that schools may reflect on how non-human arrangements relate to, encourage or disrupt the enactment of physical activity. Practices demanding physical activity required competences on the part of the 270 performers (children and adults) in order to take place. These ranged from basic 
competences such as an understanding of road safety from parents and children during

272 the walk to/from school, to more complex skills required in PE and school sport activities.

273 During a girls' lunch-time cricket club, for example, participation was observed as

274 frequently disrupted and compromised by children's limited understanding of the game

275 and ability to coordinate their bodies, the ball and bat in line with the conventions of the

276 game. The result was a somewhat chaotic experience, disrupting the practice for all

277 participants. This suggests that obvious targets for future intervention are either raising

278 competence levels of pupils or adapting the game so that less competence is required to

279 meet the demands of the practice.

280 Classroom-based teaching practices illustrate how competences imbued with

281 particular sets of associations and meanings were required for 'active learning' during

282 classroom lessons to take place. Some teachers considered the controlling of children's

283 movement in lessons to be a crucial teaching skill, reflecting understandings about teacher

284 responsibilities towards academic attainment. Asking pupils to 'sit still' and avoid

285 'fidgeting' were observed in teachers' repertoires, deployed particularly in year groups

286 engaging with state-required tests. Nonetheless, a staffroom interview with a teacher

287 revealed that active learning is possible but requires a different approach to teaching and

288 behaviour management, with new repertoires that encourage movement without allowing

289 it to be disruptive. This highlights the difficulties in overcoming 'sticking points' of

290 practices which are established and embedded in the collective conventions of a social

291 context (Hargreaves, 2011) and which relate to understandings about the role of the

292 school.

293 The social significance of physically active practices is important for how

294 practices come to be meaningful (Blue et al., 2014), and different associations had

295 constraining and enabling effects across the school. Perhaps unsurprisingly, enjoyment 
and fun were common ways that children described the physically active practices that

297 they took part in. One pupil simply said that The Daily Mile was "more fun than reading".

298 This enjoyment, however, was often accomplished through the activities being contingent

299 on other meaningful understandings such as friendship and achievement. For example, a

300 pupil explained that The Daily Mile was a good chance to "meet up with your friends",

301 and the achievement of rewards and stickers enabled positive associations and bolstered

302 the appeal of The Daily Mile. Furthermore, some children described how they had been

303 fearful of tripping during The Daily Mile before the new matting was installed, showing

304 how simple 'material' interventions might shape meanings (reduce feelings of fear) which

305 helps sustain a practice.

306 Examining practices in this way revealed the significance of individual elements,

307 but also - importantly - how the configuration of elements had emergent properties as

308 'wholes' which were not possessed by their individual component parts. Hence, the three-

309 elements of materials, competences and meanings appeared to work in combination,

310 sustaining the practice through their coherence. These practice interrelationships will

311 have local significance. In our case study school, the practice of playing football (soccer)

312 at lunchtime was constrained for some of the girls. During a focus group, one girl said

313 that "the boys won't pass you the ball if you're playing football... girls can be just as good

314 as boys." Despite the necessary physical resources (balls, goal posts and playground

315 space) being materially available, those materials were meaningfully understood as being

316 'not for girls' - an understanding linked closely to their competence (actual or perceived)

317 in performing the practice. As a result, the practice of breaktime football was a gendered

318 activity which happened in a collectively, if informally, agreed zone in the playground

319 and which generally excluded girls. Understanding practices in this way illuminates

320 where cues about social significance or meaning are embedded in the local material 
321 environment (Meier et al., 2017) and might be open to change, or where there are

322 relationships between elements that might be particularly persistent (Nettleton and Green, 323 2014).

\section{Practices in harmony and conflict}

326 For the children who walked to school, this practice was largely enabled by being in 327 harmony with the routines and goals of their parent/guardian. One parent, Jodie, explains 328 how she could carry out parenting practices with her daughters (age eight and ten) while interacting with them on the walk home; "I like to ask them [children] about their day and

330 they don't have loads of distractions. It's just us." She explained that her daughter had experienced some teasing in school recently and that these walking conversations were important parental support opportunities. Walking from school was therefore enabled by her positive associations of it as an opportunity for practicing parenting (or, perhaps, mothering) in a socio-material space free from "distractions". In this instance, the interrelationships between travelling and parenting practices are co-constitutive, tightly connected, occur simultaneously and hold each other in place (Meier et al., 2017) in a way that enables physical activity. Adding to this, walking home was further locked into place for Jodie because it synchronised with necessary domestic shopping routines.

In contrast, some pupils were driven to school because this practice was routinely enacted in combination with parents' travelling to work. As Emily (age nine) simply put

341 it, "my mum's got work every morning, so we've got to go in the car to get there on time."

342 This inter-practice relationship exemplifies what Meier et al. $(2017$, p.210) refer to as the

343 "temporal connectedness of sequences of actions". In the morning routine, the bundle of 344 practices is performed in a necessary order, and the practice of 'driving to school' outcompetes the practice of 'walking to school' because driving is better harmonised with 
346 the routines associated with parents' fixed employment schedules. As such, far from

347 being a health-related 'decision', these examples echo Blue's (2017) finding that physical

348 activity depends on the way a range of practices are synchronised; those that directly

349 support physically active practices and practices that more broadly make up everyday

350 life. Indeed, this example troubles the way in which parents can be responsibilised for not

351 enabling their child's health by not walking them to school. Furthermore, the temporal

352 organisation of practices related to fixed employment schedules or domestic labour (often

353 carried out by mothers) are likely to impose greater constraints on parents in lower

354 socioeconomic groups as well as those in more challenging geographical circumstances.

355 As such, changing 'travelling to school' practices may involve the difficult task of

356 tackling the way that children's routines are shaped by the organisation of practice

357 routines outside the school's jurisdiction (Southerton, 2013).

Other examples of the outcomes of practice interrelatedness were evident in the

enactment of The Daily Mile. The Daily Mile was generally in harmony with friendship

practices, and Dan's (age nine) description during the interview was fairly typical; my friends get here, I usually catch up to them and then we just run and just chat along the way. It's pretty fun.

However, practices are "not uniform planes upon which agents participate in identical ways" (Warde, 2005, p.138), and a few children talked about the constraining role that the enactment of friendship could have on the enactment of the running practice. Some children prioritized talking over running, which meant that these children, “don't really run. They start to talk and they don't really have a go or anything". We view this as an example of children performing a kind of friendship which is not in harmony with the physical movement ideally required for The Daily Mile, so they adapt their practice and 
373 different kinds of friendship is related to gender, something that warrants further

374 investigation given the continued gender gap in physical activity levels. Furthermore,

375 performing different kinds of friendships was relevant because, as another participant

376 explained, The Daily Mile is less enjoyable when,

there's people in front of you with big back packs that are just walking and chatting. So like, you can't get through so you have to ask. But then half the time they won't hear you and they'll just carry on chatting. So you have to go around and get your shoes a bit mucky.

In this instance, friendship enacted as "chatting" has a disruptive effect on the collective practice. As such, the organizing teleoaffective structure of practices (Schatzki, 1996), that is their purpose and emotional associations, must be considered when attempting to understand how a practice is enacted in different contexts.

Other opportunities for physical activity during the school day included walking to the local art gallery, taking class trips to the nearby park and conducting lessons in the neighbouring woodland area. Observations and discussions with teachers suggested that these opportunities were contingent on teachers who saw themselves as taking a 'progressive' or 'innovative' approach to teaching and learning. Teachers emphasised though that physically active learning opportunities were constrained by pressures relating to UK educational policies. As a teaching assistant explained,

Physical activity, I think, gets a back foot because of OFSTED valuing maths and literacy. And I think the teachers get a lot of pressure. I know they could teach in a physical way. But I think there's a lot of pressure on timetable time to fit it in.

The participant explains how the 'pressure' of academic attainment leads to physical activity through school trips and outings becoming de-prioritized. We see these educational policies as the context in which certain practices are positioned as being 'progressive', against the embedded routines of normal practice, and potentially unsustainable. Policymaking practices can be seen as co-existing in "enormous networks of action chains" (Schatzki, 1996, p.103) with powerful associations cutting across the 
nexus to inform how teaching practices become meaningful in different ways. Indeed, the

402 very idea of 'innovative' and 'progressive' physically active teaching, as identified by some of our teacher participants, suggests that they were pushing against collective conventions relating to quiet, sedentary classes. supportive and encouraging school leadership, an example of teaching practices being in

407 harmony with localised (school-level) leadership practices. This supports the assertion that in the right practice conditions, practitioners can shape their engagement with practice routines. As the crossing points of multiple practices (Reckwitz, 2002), teachers acting within harmonious practice configurations can facilitate localised change to enable

411 the emergence of physical activity, just as parents can integrate a walk to school with

412 shopping, parenting or a trip to the park. However, this is only possible if the practices 413 they are enacting collaborate appropriately.

\section{Conclusion}

415 In an attempt to advance an understanding of how practice theories might inform public

416 health research and intervention, this study has made a distinctive contribution by

417 applying the three-elements model to the context of children's physical activity during a

418 school day. First, it illuminates how a practice theory approach to physical activity can

419 be applied as a theoretical lens to reveal the complex ways that school-based physically 420 active practices are enabled and constrained. The three-elements analysis reveals the 421 contingent nature of a primary schools' physically active practices. Analysis has shifted 422 focus away from individuals to the different ways that physical activity emerges from 423 practices for which it is a requirement, such as travel to school, or part of its purpose, such as PE. The ways that physical activity emerges depends on the configurations of 425 practice elements which are drawn on in the enactment of practices, and also on practice 
interrelationships across the nexus. Our analysis has illustrated how physically active

427 practices can be supported when there is harmony with related practices, and constrained

428 when there is conflict (Shove et al., 2012). Further research may include consideration of the way persistent sedentary practices compete with physical activity. A practice theory understanding of physical activity would frame the goals of intervention in terms of shaping a nexus which supports routine, habitual physical activity.

Second, our analysis begins to illuminate the focus of interventions required to create habitual physical activity. For example, the practices implicating children's physical activity might be in conflict or harmony with routines, practices and policies that may have been otherwise invisible, but which create important connections. We found connections between attainment and calmness in classrooms, between gender and sports, and between parenting and working and active travel to school. There are important human and non-human coordinators of practice, such as teachers and parents, policies, timetables and material structures. A three-elements analysis provides one way of understanding this complexity, by illuminating contingent eco-systems or processes, rather than influences or causes (Shove et al., 2012). As such, it illuminates the need for

442 intervention which has multiple strands and purposes, engages multiple actors, partners and stakeholders and is able to emerge and change over time (Lang and Rayner, 2007). practice-based intervention might be implemented within such a complex school system, especially given the disappointing outcomes of other 'whole school' physical activity interventions (Adamowitsch et al., 2014). Furthermore, there are questions about how changes to the practice nexus might be evaluated when the ways that the dynamic configuration of practices might evolve cannot be predicted (Keane et al., 2017). 

the three-elements model as a framework for analysis, which is important given the growing prevalence of its use in practice-oriented critical public health. We are sympathetic to Watson's (2017) comment that although the three-elements "has provided

454 the basis for attempts to reconceptualise possible targets for intervention... it has little to say about the means through which power operates" (p.172). Power relations across the nexus are important for the way practices interrelate, are made possible and change. For example, power is implicated in the way that health and safety and attainment policies can be privileged when competing with physical activity. Power is also central in the supportive leadership which enabled our teacher participants to enact 'progressive', 460 physically active teaching practices. Power is, of course, also present in the notion of 461 intervention, in terms of who has the legitimacy to impose a programme of change. The three-elements model emphasises practice co-existence and obscures how and why "some practices and practitioners are able deliberately to affect the conduct of practices and

464 practitioners elsewhere" (p.173). For example, the unequal capacity for practitioners to overcome employer obligations and walk their children to school is not easily accounted 466 for. The danger is that power and politics become 'bracketed off' (Cohn, 2014), when they are central to the social processes involved in social change.

We conclude that despite important limitations, the three-elements model offers a helpful framework for understanding school physical activity which de-centres the 470 individual and focuses on the social processes from which habitual physical activity does, 471 or could, emerge. However, its capacity to effectively support interventions which challenge and shape routinized patterns of action is yet to be demonstrated (Hargreaves, 2011). Future research can pursue the research agenda that this paper opens up, and explore the implications of practice-oriented intervention across the practice nexus 
475 (Houlihan and Browne, 2019) for the purposes of shaping children's routinized physically 476 active practices during a school day.

477 
Abarca-Gómez, L., Abdeen, Z.A., Hamid, Z.A., et al. (2017), Worldwide trends in bodymass index, underweight, overweight, and obesity from 1975 to 2016: a pooled analysis of 2416 population-based measurement studies in 128.9 million children, adolescents, and adults. Lancet, 0(0), 1-16.

Ally, A.K., Lovatt, M., Meier, P.S., Brennan, A., \& Holmes, J. (2016). Developing a social practice-based typology of British drinking culture in 2009-2011: implications for alcohol policy analysis. Addiction, 111, 1568-1579.

Barnfield, A. (2016). Grasping physical exercise through recreational running and nonrepresentational theory: a case study from Sofia, Bulgaria. Sociology of Health \& Illness, 38(7), 1121-1136.

Baum, F., \& Fisher, M. (2014). Why behavioural health promotion endures despite its failure to reduce health inequities. Sociology of Health \& Illness, 36(2), 213-225.

Blue, S. (2017). Maintaining physical exercise as a matter of synchronising practices: Experiences and observations from training in Mixed Martial Arts. Health \& Place, 46, 344-350.

Blue, S., Shove, E., Carmona, C., \& Kelly, M.P. (2016). Theories of practice and public health: Understanding (un)healthy practices. Critical Public Health, 26, 36-50.

Bourdieu, P. (1977). Outline of a theory of practice. (R. Nice, Trans.). Cambridge: Cambridge University Press. Bourdieu, P. (1980). The logic of practice. Stanford, CA: Stanford University Press.

Bourdieu P. (1984). Distinction: A social critique of the judgement of taste. Cambridge, MA: Harvard University Press.

Cohn, S. (2014). From health behaviours to health practices: An introduction. Sociology of Health \& Illness, 36, 157-162.

Das, P. \& Horton, R. (2016). Physical activity - time to take it seriously and regularly. The Lancet, 388(10051), 1255-1256.

Department of Health (2008). Healthy Weight, Healthy Lives: a Cross-Government Strategy for England. Retrieved from https://extranet.who.int/nutrition/gina/sites/default/files/GBR\%202008\%20Healt hy $\% 20$ Weight $\% 2 \mathrm{C} \% 20$ Healthy $\% 20$ Lives- $\% 20 \mathrm{~A} \% 20$ CrossGovernment $\% 20$ Strategy\%20for\%20England.pdf

Elhakeem, A., Cooper, R., Bann, D., Kuh, D., \& Hardy, R. (2017). Birth weight, school sports ability and adulthood leisure- time physical activity. Medicine and Science in Sport and Exercise, 49(1), 64-70.

Giddens, A. (1984). The constitution of society: Outline of the theory of structuration. Berkley: University of California Press.

Guell, C., Panter, J., Jones, N.R. and Ogilvie, D. (2012). Towards a differentiated understanding of active travel behaviour: Using social theory to explore everyday commuting, Social Science and Medicine, 75(1), 233-239.

Hargreaves, T. (2011). Practice-ing behaviour change: applying social practice theory to pro- environmental behaviour change. Journal of Consumer Culture, 11(1), 7999.

Houlihan, C. and Browne, A. (2019). Change Points: A toolkit for designing interventions that unlock unsustainable practices. Manchester University [online]. Available from https://nexusathome.files.wordpress.com/2018/11/change-points 1.pdf.

Keane, H., Weier, M., Fraser, D., \& Gartner, C. (2017). 'Anytime, anywhere': vaping as social practice. Critical Public Health, 27(4), 465-476.

Kelly, M. and Barker, M. (2016). Why is changing health-related behaviour so difficult? Public Health, 136, 109-116 
Kincheloe, J. L. 2005. "On to the Next Level: Continuing the Conceptualization of the Bricolage." Qualitative Inquiry 11: 323-350.

Lai, S.K., Costigan, S.A., Morgan, P.J., Lubans, D.R., Stodden, D.F., Salmon, J., \& Barnett, L.M. (2014). Do school-based interventions focusing on physical activity, fitness, or fundamental movement skill competency produce a sustained impact in these outcomes in children and adolescents? A systematic review of follow-up studies. Sports Medicine, 44(1), 67-79.

Lang, T. and Rayner, G. (2007). Overcoming policy cacophony on obesity: an ecological public health framework for policymakers. Obesity Reviews, 8(1), 165-181.

LeBesco, K. (2011). Neoliberalism, public health, and the moral perils of fatness. Critical Public Health, 21(2), 153-164.

Love, R., Adams, J. and van Sluijs, E.M.F. (2019). Are school-based physical activity interventions effective and equitable? A meta-analysis of cluster randomized controlled trials with accelerometer-assessed activity. Obesity Reviews, 1-12.

Lytle, L.A., Seifert, S., Greenstein, J. and McGovern, P. (2000). How do children's eating patterns and food choices change over time? Results from a cohort study. Am J Health Promot, 14, 222-228.

Mackintosh, K.A., Knowles, Z.R., Ridgers, N.D., \& Fairclough, S.J. (2011). Using formative research to develop CHANGE!: A curriculum based physical activity promoting intervention. BMC Public Health, 11, 831-844.

Maller, C. (2015). Understanding health through social practices: performance and materiality in everyday life. Sociology of Health and Illness, 37(1), 52-66.

McLeroy, K.R., Bibeau, D., Steckler, A., \& Glanz, K. (1988). An ecological perspective on health promotion programs. Health Education Quarterly, 15(4), 351-77.

Meah, A., \& Jackson, P. (2018). Convenience as care: Culinary antinomies in practice. Environment and Planning A, 49(9), 2065-2081.

Meier, P.S., Warde, A., \& Holmes, J. (2017). All drinking is not equal: how a social practice practice theory lens could enhance public health research on alcohol and other health behaviours. Addiction, 113, 206-213.

Mykhalovskiy, E., Eakin, J., Beagan, B., Beausoleil, N., Gibson, B.E., Macdonald, M.E., Rock, M.J. (2018). Beyond bare bones: critical, theoretically engaged qualitative research in public health. Canadian Journal of Public Health, 109(5), 613-621.

Nettleton, S., \& Green, J. (2014). Thinking about changing mobility practices: how a social practice approach can help. Sociology of Health \& Illness, 36(2), 239-251.

Powell, K., Thurston, M., \& Bloyce, D. (2017). Theorising lifestyle drift in health promotion: explaining community and voluntary sector engagement practices in disadvantaged areas. Critical Public Health, 27(5), 554-565.

Reckwitz, A. (2002). Toward a theory of social practices: a development in culturalist theorizing. European Journal of Social Theory, 5, 243-263.

Rettie, R., Burchell, K., \& Riley, D. (2012). Normalising green behaviours: A new approach to sustainability marketing. Journal of Marketing Management, 28(34), 420-444.

Scambler, G. (2009). Health-related Stigma. Sociology of Health \& Illness, 31(3), 441455.

Schatzki, T. (2002). The site of the social: A philosophical account of the constitution of social life and change. University Park, PA: Pennsylvania State University Press.

Shove, E. (2010). Beyond the ABC: climate change policy and theories of social change. Environment and Planning A, 42(6), 1273-1285. 
601

602

603 604

Shove, E., \& Pantzar, M. (2005). Consumers, Producers and Practices Understanding the invention and reinvention of Nordic walking. Journal of Consumer Culture, 5(1), 43-64.

Shove, E., Pantzar, M., \& Watson, M. (2012). The Dynamics of Social Practice: Everyday Life and How it Changes. London: Sage.

Supski, S., Lindsay, J., \& Tanner, C. (2017). University students' drinking as a social practice and the challenge for public health. Critical Public Health, 27(2), 228237.

Twine, R. (2015). Understanding snacking through a practice theory lens. Sociology of Health \& Illness, 37(8), 1270-1284.

Vihalemm, T., Keller, M., \& Kiisel, M. (2015). From Intervention to Social Change: A Guide to Reshaping Everyday Practices, Ashgate Publishing, Farnham.

Watson, M. (2017), 'Placing power in practice theory', In The Nexus of Practices, Hui, A., Schatzki, T. and Shove, E. (eds), London: Routledge.

World Health Organization (2018). Noncommunicable diseases. Retrieved from http://www.who.int/news-room/fact-sheets/detail/noncommunicable-diseases

Williams, O. (2017). Identifying adverse effects of area-based health policy: an ethnographic study of a deprived neighbourhood in England. Health \& Place, 45, 85-91.

Wiltshire, G., Lee, J., \& Evans, J. (2017). 'You don't want to stand out as the bigger one': exploring how PE and school sport participation is influenced by pupils and their peers. Physical Education and Sport Pedagogy, 8989 (March 2017), 1-14. http://doi.org/10.1080/17408989.2017.1294673

Wiltshire, G., Fullagar, S., \& Stevinson, C. (2017). Exploring parkrun as a social context for collective health practices: Running with and against the moral imperatives of health responsibilisation, Sociology of Health \& Illness, 40(1), 3-17.

Acknowledgements. Some of the first author's contribution was carried out at the University of the West of England. 
606 1. Moderator's guide for Daily Mile interviews

607 2. Moderator's Guide for Pupil Focus Groups

608 3. Moderator's Guide for Staff Interviews

609 4. Observation Guide

610

611

612

613

614

615

616

617

618

619

620

621

622

623

624

625

626

627

628

629

630

631

632

633

634

635

636

637

638

639

640

641

642

643

644

645

646

647

648

649

650

651

652 


\begin{tabular}{|l|l|}
\hline Section & Questions \\
\hline $\begin{array}{l}\text { Introductory } \\
\text { questions }\end{array}$ & $\begin{array}{l}\text { How long has this school been doing the Daily Mile? } \\
\text { Does everyone enjoy doing the Daily Mile? }\end{array}$ \\
\hline Meanings & $\begin{array}{l}\text { - Why do you enjoy / not enjoy the Daily Mile? } \\
\text { - Not every school does the Daily Mile, why do you think this school } \\
\text { does it? } \\
\text { - How does it make you feel before/during/after? } \\
\text { - What's the first thing you think of when you think of the Daily Mile? }\end{array}$ \\
\hline Materials & $\begin{array}{l}\text { - What can you see when you run around? } \\
\text { - What does the ground feel like when you are running? } \\
\text { - What can you hear and smell when you are running? } \\
\text { - Are there other places at home or near your house where you could also } \\
\text { do the Daily Mile? } \\
\text { - Does it matter what you are wearing when you run? }\end{array}$ \\
\hline Competences & $\begin{array}{l}\text { - Do you find the Daily Mile hard, easy or somewhere in between? } \\
\text { - When you start, do you feel confident that you will finish? } \\
\text { - Are you good at running and walking? Why? } \\
\text { - Do you ever compare yourself of other people in your class? } \\
\text { - Do you feel like you are fit? } \\
\text { - Do you feel like you are healthy? }\end{array}$ \\
\hline
\end{tabular}




\begin{tabular}{|c|c|}
\hline Section & Activity and questions \\
\hline $\begin{array}{l}\text { Introduction and } \\
\text { warm up }\end{array}$ & $\begin{array}{l}\text { - Thanks for taking part. } \\
\text { - Information and consent. } \\
\text { Icebreaker 1: Imagine you could go on holiday anywhere for a whole week. What } \\
\text { would you choose to do? } \\
\text { Icebreaker 2: Get up and move around - talk to each other and work out who lives } \\
\text { the furthest away from school. Order yourselves across the room. }\end{array}$ \\
\hline Your school & $\begin{array}{l}\text { - } \quad \text { Tell me about your school. What do you like about it? } \\
\text { - } \quad \text { How would you describe your school to an alien? (Facilitator draw } \\
\text { picture son the flipchart as children describe). } \\
\text { - } \quad \text { What would you change if you were in charge? }\end{array}$ \\
\hline Your day & $\begin{array}{l}\quad \text { Tell me about your school day. } \\
\text { ACTIVITY: } \\
\text { Draw before school, morning, lunch, afternoon and after school... something you } \\
\text { do (one point in the day per child). } \\
\text { What is your favourite way of spending time? }\end{array}$ \\
\hline $\begin{array}{l}\text { Being physically } \\
\text { active }\end{array}$ & $\begin{array}{l}\text { - What does it mean to be physically active? } \\
\text { - } \quad \text { What activities do you do that get you breathing hard? Let's act them out. } \\
\text { - } \quad \text { How does it feel to be physically active? What do you like about it? } \\
\text { Parents and teacher: } \\
\text { - Do your parents do physical activity? What about your teachers? } \\
\text { - } \quad \text { Tell me what they do. } \\
\text { - } \quad \text { Do you think they like it? }\end{array}$ \\
\hline $\begin{array}{l}\text { Physically } \\
\text { activity culture }\end{array}$ & $\begin{array}{l}\text { ACTIVITY } \\
\text { DICE with a story stem on each side. Create a short story by rolling the dice. Sit in } \\
\text { a circle. Facilitator writes story on flipchart. TALKING STICK, teddy etc. } \\
\text { 1. Tom was really good at running. He was fast and he liked playing } \\
\text { football and was a brilliant swimmer. His best friend, Sam, didn't like } \\
\text { running about and Tom was sad about this. One day at lunch, Tom } \\
\text { decided they would do something really exciting... } \\
\text { 2. A group of friends from year? got together one Saturday to play. They } \\
\text { were sitting sipping some lemonade in a sunny garden, trying to decide } \\
\text { what to do. Suddenly, Poppy came up with a great idea... } \\
\text { 3. Jamie's parents were surprised when Jamie asked to join the school } \\
\text { cycling club. They thought that... } \\
\text { 4. Georgie was a new girl at the school. It was her first day. Some of the } \\
\text { other children in her class went up to her at break and said "you can play } \\
\text { with us". She was very glad to have some new friends. They all went } \\
\text { together to... } \\
\text { 5. Martha was so excited to get home from school and tell her parents what } \\
\text { she had been asked to join in with the next day. She was going to be part } \\
\text { of the... } \\
\text { 6. It was a rainy, cold, wintery day and Josh and his friends were a bit } \\
\text { bored. They were trying to decide what to do. In the end, they decided } \\
\text { to... }\end{array}$ \\
\hline Wrap up & $\begin{array}{l}\text { Would you like to do more things that are physically active? What would you like } \\
\text { to do? } \\
\text { Thank you! (Distribute stickers) }\end{array}$ \\
\hline
\end{tabular}




\section{Moderator's Guide for Staff Interviews}

\begin{tabular}{|c|c|}
\hline Section & Activity and questions \\
\hline Introduction and warm up & $\begin{array}{l}-\quad \text { Thanks for taking part. } \\
-\quad \text { Information and consent. } \\
\text { Icebreaker - How long have you taught here? What are you doing over } \\
\text { the summer? }\end{array}$ \\
\hline Your school & $\begin{array}{l}\text { - } \quad \text { Tell me about the school. What do you like about it? } \\
\text { - } \quad \text { How would you describe your school to an alien? } \\
\text { whe one thing you would change about it if you could } \\
\text { wave a mand? }\end{array}$ \\
\hline Your leisure time & $\begin{array}{l}\text { - I know how hard teachers work... Tell me about your } \\
\text { weekends. } \\
\text { - Favourite way of relaxing. What's your one luxury that you } \\
\text { wouldn't do without }\end{array}$ \\
\hline Being physically active & $\begin{array}{l}\text { - } \text { What does that mean? } \\
\text { - } \quad \text { How do you feel about doing 'sport' or 'being physically } \\
\text { - } \quad \text { What do you do that is active? } \\
\text { - } \quad \text { Where do you do them? } \\
\text { - } \quad \text { Some people don't like being physically active. Why do you } \\
\text { think that is?] } \\
\text { How physically active do you think children at your school are? } \\
\text { What would make them more active? } \\
\text { What about out of school? How much physical activity do you think the } \\
\text { children do when they're not here? }\end{array}$ \\
\hline Physically activity culture & $\begin{array}{l}\text { ACTIVITY } \\
\text { Let's write a list of all the places and times that children are physically } \\
\text { active in school. I'll start: } \\
\quad \text { - Some walk or cycle to school... } \\
\text { Let's write a list of all the times they are sedentary: } \\
\quad \text { - Eating their lunch }\end{array}$ \\
\hline Wrap up & $\begin{array}{l}\text { Would you like to do more things that are physically active? What } \\
\text { would you like to do? }\end{array}$ \\
\hline
\end{tabular}




\section{Observation Guide}

\section{Topics of interest for observation (non-exhaustive) for Drop-offs, Pick-Ups, Playground Activities, and PE Classes}

SPACE - What is the physical layout of the space, what does the area look like, what is in the immediate proximity of the setting, what surrounds it etc.?

OBJECTS - What are the physical things/objects that are present? (e.g. cars, street signs, road infrastructure etc.)

EVENT - What is the main event that is taking place, what is the purpose of the event?

ACTOR(S) - Who are the range of people involved? (Estimation of numbers over the observations period, demographics and general characteristics; are there actor groups, are some actors more dominant than others?)

INDIVIDUAL ACTS - what are the single/discrete acts that are taking place? (Getting out of a car etc.)

ACTIVITIES - Are there groups of behaviour acts that seem to be related? (E.g. single actions such as: parking, getting out of the car, saying goodbye etc.)

TIME and SEQUENCING- What is the time of day, day of the week, time of the month, season etc. How long do activities take? Is there anything interesting about the sequencing of events?

GOAL(S) - What are the goals that people are trying to accomplish?

FEELINGS - What are the emotions that are being felt and expressed? How are these expressed etc.? 